The following Paper received the Second Place, Under the category of Over 35 years of age at the "Water Related Infrastructure" Competition 2003/2004, Sponsored by the

St. Anthony's Industries Group (Pvt) Ltd.

\title{
A Surface and Groundwater Supply System Study Project for better Management
}

\author{
N. T. S. Wijesekera, T. A. Peiris, N. P. D. Gamage, A. A. Kodippli, P. P. Ghanapala, \\ C. B. Amarasinghe, G. K. De S. Ginige
}

\section{Introduction}

\subsection{General}

Water Management is a very important task for an organisation located in a water scarce area requiring significant quantities of water for its production process and for the domestic use of its employees. This is especially important when a significant amount of energy is utilised to extract, circulate and distribute water, and yet experiencing issues such as insufficient water, inadequate pressure, leaking storages, overflowing reservoirs etc. In such situations, the obvious options are either to expand the supply, redo the pipe layout, replace and add pumps, or to have a combination of these. These decisions may be easy in the case of simple layouts. However when a system has to consider investments for additional groundwater wells, additional water extraction pumps, re-laying of pipes, shedding users, obtaining environmental approvals for water extractions etc., in a distribution area which covers approximately $180 \mathrm{ha}$, and having supply pipe lines laid over distance more than $7 \mathrm{~km}$, the management has to be cautious when selecting the appropriate solution. Therefore any rational manager requires to undertake a project where a comprehensive study is done for the entire water supply and distribution system in order to identify rational management options. Such a study is not only important in terms of an organisation that is looking at the type of options mentioned above, but also in the context of the nation because any irrational extractions either from groundwater or surface water would be critical in a regional context.

\subsection{The Project}

The project described in this paper is the study of water supply network and sources, of the system covering Factory compound and housing area shown as Puttalam Cement Company in Figure 1. Water supply network of the Cement Company consists of two independent pipe networks distributing water for cooling and drinking purposes. Cooling water network circulates water that cools the production process and any loss is supplemented by water extracted from the surface water body named Mee Oya and pumped to the factory almost throughout the day. Drinking water extracted from deep wells is supplied using two networks. One gets the supply from two groundwater wells located near the old airstrip at Palavi, which is approximately $2 \mathrm{Km}$ away and the other from a tube well near the housing area within the compound. The cooling water system operates throughout the day while the drinking water is supplied intermittently. A significant number of storage tanks both surface and overhead types support both these networks. A set of electric pumps connected to both networks also enable the maintenance of requisite pressure heads for water distribution. Lack of flow and pressure measurements of both factory and domestic systems and the lack of as-built plans of the pipe

Eng. (Prof.) N.T..S. Wijesckera - BSr. Eng.(Hons) Sri Lankn. PG Dip (Moratuna), M.Eng.(Tolyon), D.Eng.(Tolyo), C.Eng., MICE(London), FIE(Sri Lanka). Professor of Ciril Engineering and the Chaiman of the Intemational Center for Gesinformatics Applications and Training at University of Moraluwa

Eng. (Dr.) T. A. Peiris- BS: Eng.(Hons). DIC. MSc(London), D. Eng.(Tokyo), C. Eng., MIE(Sri Lanka). Senior Lecturer of the Department of Civil Engineering, University of Moratuwa

Eng. (Dr.)N P D Gamage - BSt: Eng.(Hons), MSr,(Galway) PhD(Saitama) C. Eng., MIE(Sri Lanka). Senior Lectuner of the Depanment of Civil Engineering, University of Morntuwn

Eng. A. A. Kadippli - BSr, Geology), MIMM, MIAH, C.Eng. Formerly the Geologist at National Water Supply and Drainage Boumt. Ralmalana. Presiently residing in Canada

Eng. P. P. Ghannpala -BSc Eng.(Hous), MSt, (Netherlands), C. Eng.. MIE(Sri Lanka), MICE (London). Deputy Genemal Manager, Sri Lankn Land Rerlanmation and Development Corporation. Sri Jnyawandennpum Eng. C. B. Amnrasinghe - BSc. Eng.(Hons), Senior Engineer, Sri Lankn Land Reslamation and Development Corporation. Sri Jajnwardennupum Eng. C. K. De S. Ginige - BSe Eng.(Honns) Moratuwn, Presently purxulung Posigrndunte studies in the United Sintes of America and formerly civil engineer al Samuel and Sons Ldt. Colombo 


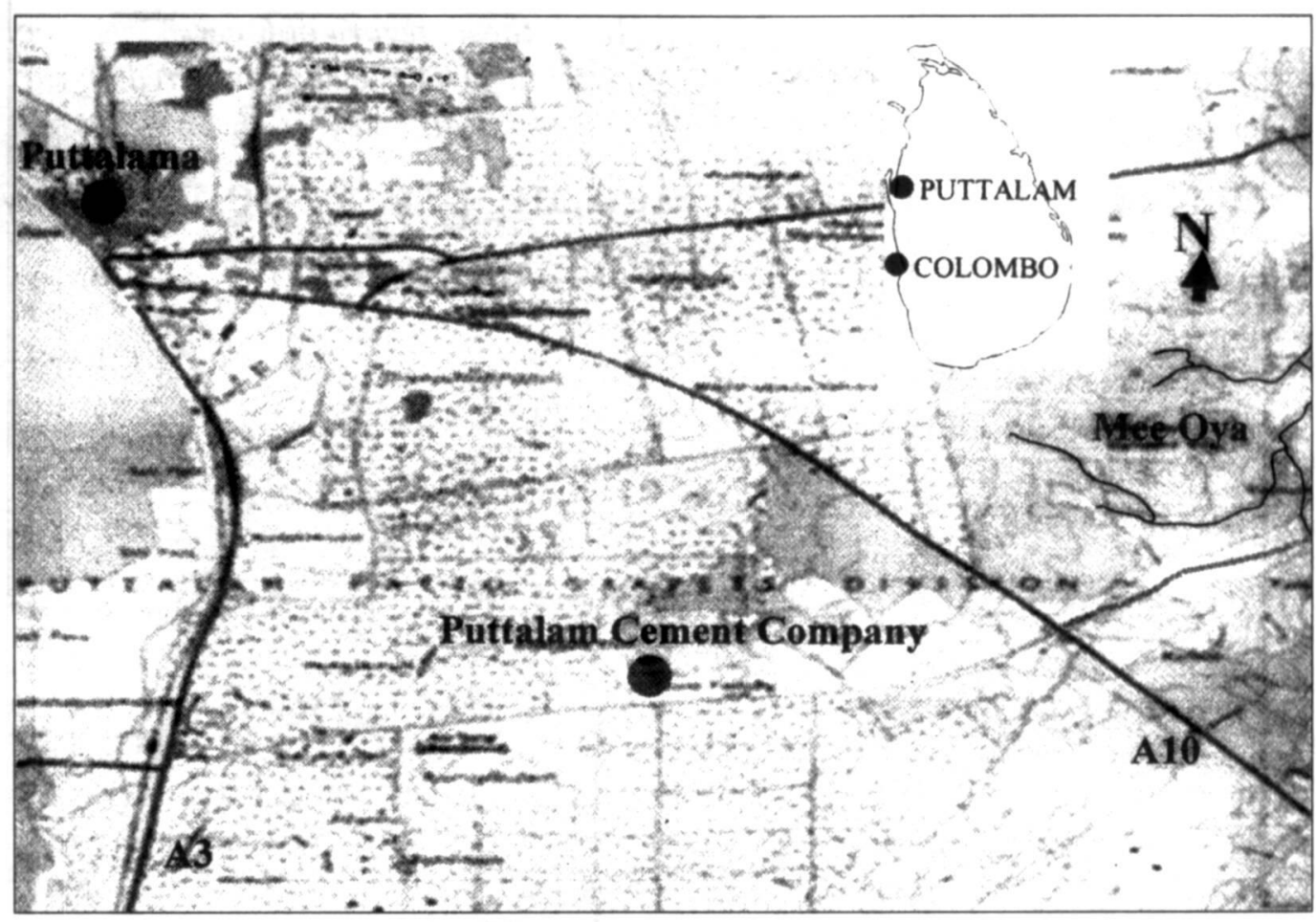

Figure 1: Location of the Project

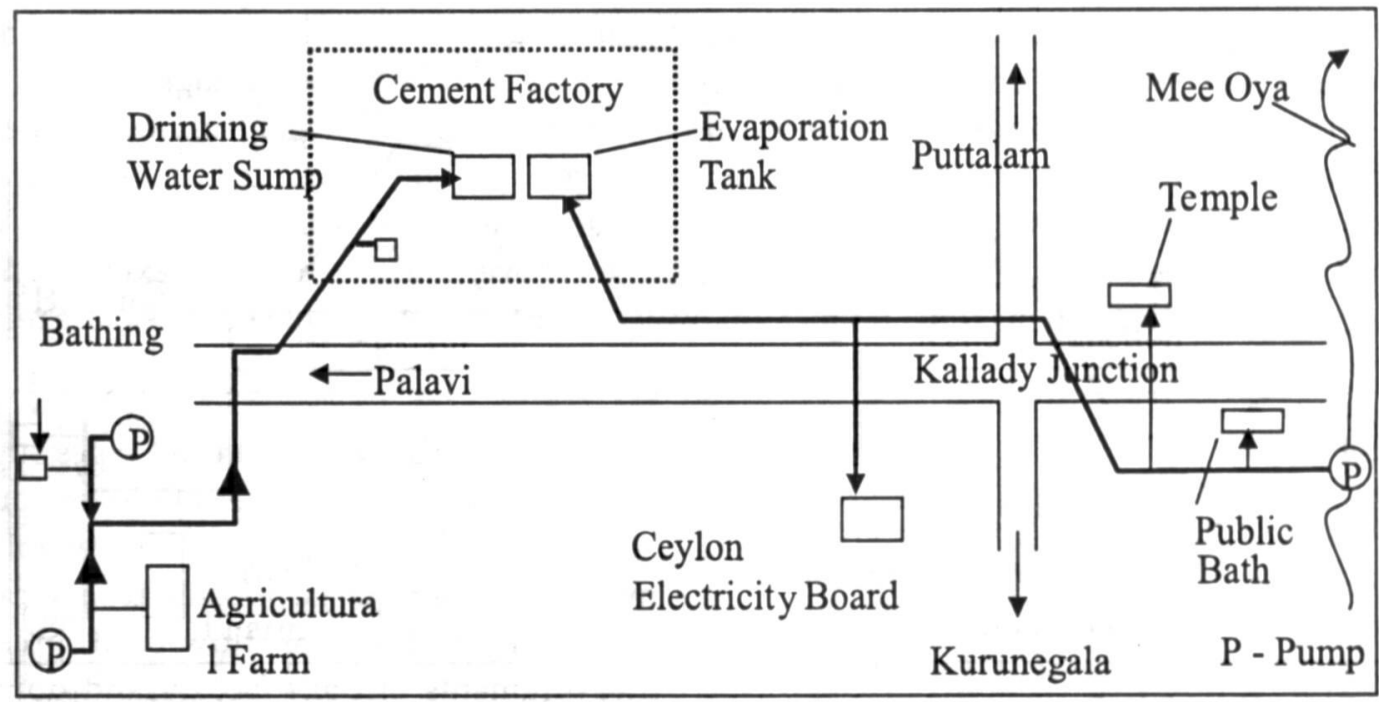

Figure 2: Schematic Diagram of the Water Mains Belonging to the Puttalam Cement Company and the External Extraction from Same

network were the major concerns for a detailed study.

The schematic diagram of main water carrying pipe lines to the factory premises and housing area are shown in Figure 2.

\subsection{Activities}

An assessment of the system and the activities necessary to be carried out was done through a comprehensive initial investigation. This work identified that the activities needs to be within the four following broad areas; 1) Water supply and usage for factory and housing scheme, 2) Study of the cooling water supply and storage system. 3) Groundwater investigation and 4) Surface water investigation.

Identification of the present sources and to estimate the extraction rates, identification of the supply and storage network and the status, estimation of the consumption rates in the factory and housing scheme, identification of pressure distribution in the water supply network, picking up source details, identify pump details, and operation details, picking up the pipe network pipe layout, pipe diameters, and type of pipe, 
picking up the status of pipes and pumps, verification of field information, development of a computer model of the water supply network, pipe network analysis using the computer model, carrying out pipe pressure and flow measurements, and measurement of usage patterns within the day and within the week, were the items carried out under the item 1 above.

In the item 2, the activities carried out by the study were, identification of cooling water supply sources, extraction rates and storage system, identification of pipe network and present status, Survey and measurement the existing usage and patterns, measurement/estimation of inflow and outflow in the main system and in storage reservoirs, measurement of temperature variation in the system path and storages, collection of regional ambient conditions and water balance/ energy balance modelling to analyse the sub systems/main system.

In case of the groundwater investigation, collection of available groundwater data of the region, a field survey to establish present usage in the concerned region, carrying out pumping tests for yield estimates, development of a mathematical model for groundwater aquifer, identification of present nature of extractions and analyse future scenario, were the activities carried out.

The surface water source investigation consisted of the collection of available rainfall, evaporation \& streamflow data of the region, development of a mathematical model for the watershed of the surface water source, and identification of the present status \& analyse future scenario.

The present usage, actual requirements, wastage, recommendations for improvements were presented as outputs of each section along with maps, tables and figures. Detailed descriptions, data, calculation methods and results, maps, tables and figures are documented in Wijesekera et al 2000.

\section{Materials and Methods}

\subsection{Data Collection}

Layout and the elevations of pipes in the network were established by an engineering survey. This included the identification of pipe locations, diameters and pipe status. Flow and pressure measurements were carried out at identified key nodes of the network. An extensive demand survey at both the factory premises and the housing area was carried out to identify the water use, number of outlets, type of usage, users during daytime and night-time etc. Water use was metered at selected points once a day for five weeks and at approximately 30-minute intervals for three consecutive days to identify the consumption rates and the pattern pertaining to the study area. Sufficiently long pipe sections from various locations and of different diameters were removed from the pipe network for laboratory testing. Short pipe lengths were sectioned to inspect the degree of clogging in the pipes. Rates of inflow from groundwater wells near the old airstrip and from the Mee Oya were measured.

Pumping tests were performed at all five tube wells belonging to the Puttalam Cement Company. A groundwater user survey and a dug well survey within about 40 square kilometres were performed to collect information for a mathematical ground water model established for the concerned project area. Survey included the collection of well-logs and pumping rates of the tube wells. In case of dug wells, data such as present type of use, quantity of usage, quality of water, average, maximum and minimum water levels, were collected. Electrical conductivity of dug wells that were identified at the survey was measured to study the groundwater.

Temperature variations in the cooling water circuit and at many locations in the pond were recorded over three days to analyse the performance of the evaporation pond. The cooling pond has a surface area of $36 \mathrm{~m} \times 36 \mathrm{~m}$ and a depth of $0.7 \mathrm{~m}$ and this is used for circulation, cooling and mixing of supplementary water from Mee Oya. The monthly data of ambient conditions were obtained from the Puttalam meteorological station.

Samples at a few selected locations of the network including the water sources and sumps were tested for water quality. Temperature, $\mathrm{pH}$, Electrical conductivity, Colour, Dissolved Oxygen, Suspended Solids, Hardness, Sulphates, Iron, Manganese, Alkalinity, Fluoride, Chlorides and Coliforms were selected as critical parameters to reflect quality of water. 


\subsection{Analysis}

\subsubsection{Pipe Network Modelling And Water Balance}

Pipes of different diameters were subjected to laboratory testing for computation of typical friction factors of used pipes for pipe network modelling. Pipe Network for housing and factory area (Figure 3) were separated into nine sub area networks for analysis. Sub mains are laid out along the pathway/roadway to provide water for housing units by means of either $1 / 2^{\prime \prime}$ or $3 / 4^{\prime \prime}$ diameter pipes. In order to avoid network complexities, the analysis considered the pipes as up to the sub mains in the roads/pathways. Analyses of the main artery network without house connections enabled the identification of the performance of common pipes and valves. Another reason for this representation of the network in the model was because the pipe cross section inspections indicated that smaller diameter pipes were the most clogged ones and that pipes of diameter greater than $2^{\text {" were not }}$ seriously affected. As such, after initial computations, attempts were made to establish the degree of clogging at individual housing links. Pressures from the main arteries were used as inputs for subsequent computations. The pipe network incorporated the elevations of inlets, outlets \& pipe junctions, pipe diameters, pipe roughness, etc. The flow analysis used the HazenWilliam formula where the defined friction coefficient decreases with increased friction in the pipes. Modelling exercise systematically analysed the network capability and the adequacy of layout, simulated the present status, and identified reasons and remedial measures that need to be incorporated. The computations used a friction coefficient of 100 for relatively new pipes whereas a value of 57 observed from laboratory test results was taken to represent a severely clogged condition. Network

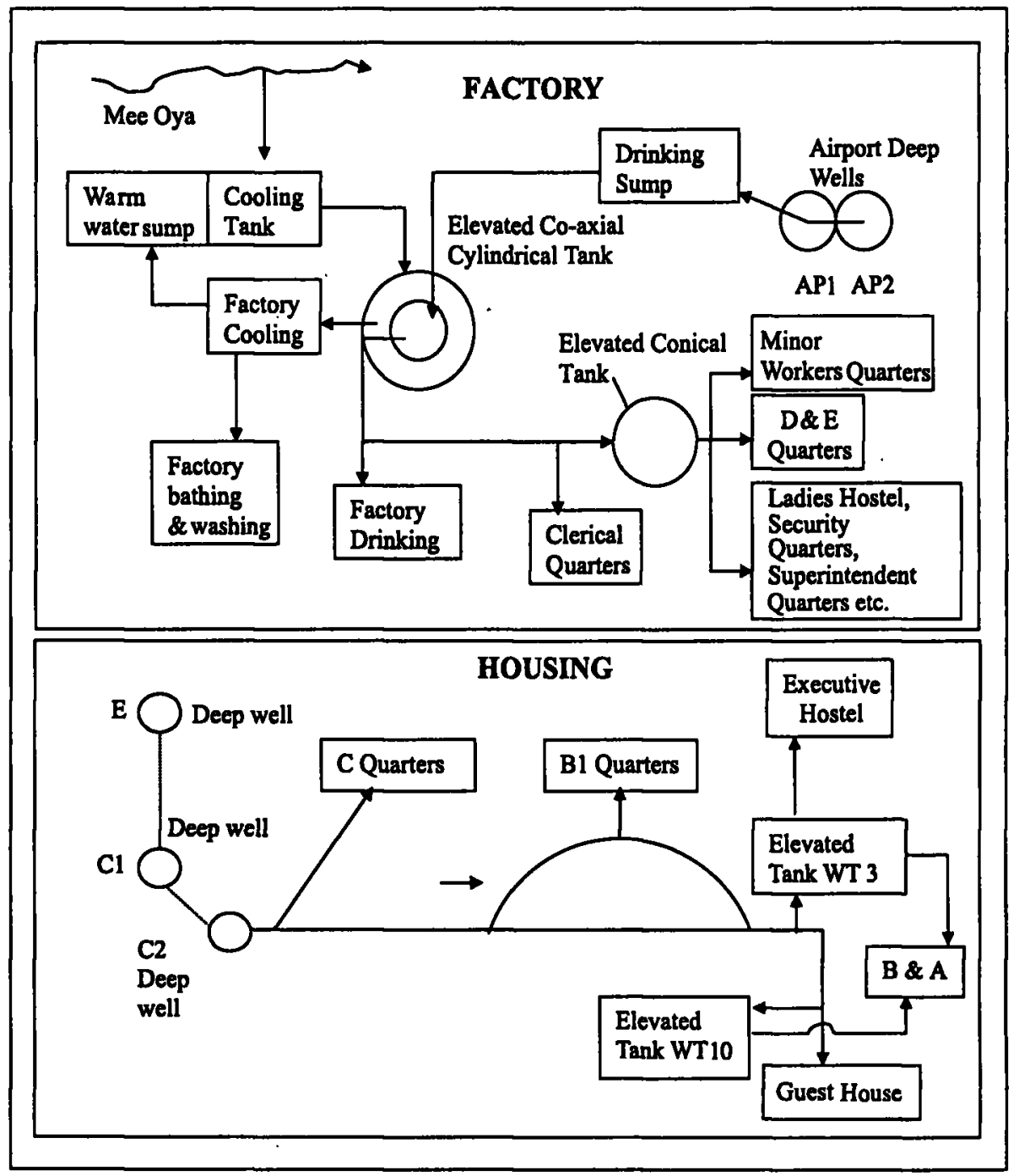

Figure 3: Schematic Diagram of the Water Distribution System of the Factory Premises and the Housing Area 
performance in each sub system was done considering minimum and maximum demands captured during field observations. These values were varying from $0.081 / \mathrm{s}(11 \mathrm{l} / \mathrm{d})$ to $0.15 \mathrm{l} / \mathrm{s}(208$ $1 / d)$. Analysis was to identify the system behaviour for these observed values. Typical cases and outputs pertaining to those are shown in Figure 4.

In the two systems for drinking purposes and cooling purposes, water balance computations were done by equating inflow outflow and change in storage in a daily time scale considering the average and maximum values. The data availability did not permit computations of water balance at a specific time period. Hence the measured average and maximum values were used separately for water balance to identify the range of losses and other quantities in the system. Flow components identified during water balance computations and pertaining to each system are indicated in the Figures 5 and 6.

\subsubsection{Groundwater Supply System}

Pumping test data were analysed to estimate the safe yields and identify suitable duration for pumping groundwater from respective wells. Groundwater system influencing the deep wells of the Puttalam Cement Company and its vicinity was mathematically modelled using a three dimensional computer model and validated to assess the long term sustainability. Groundwater levels in the project area indicated a water divide to the east of Puttalam Cement Company and the groundwater flow almost in the East West Direction. The existence of a groundwater depression was identified closer to the Northern boundary indicating the recharge, area. Model limits were established using such interpretations of the data from the field surveys (Figure "*). Model inputs consisted of soil types and sub strata information, dug well and tube well water levels, rainfall, evaporation and the behaviour of the model boundaries. Model cells were established

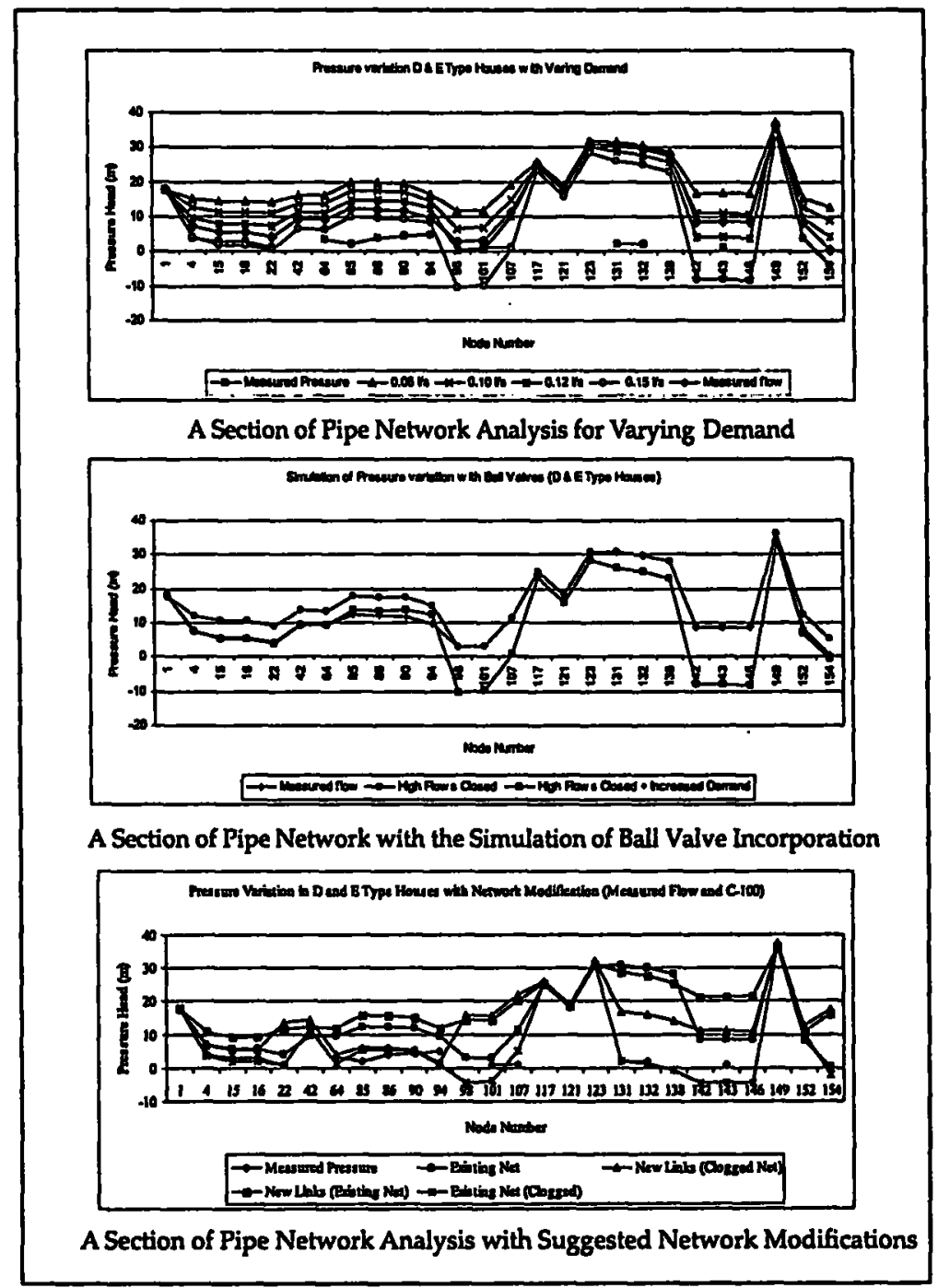

Figure 4: Typical Outputs from Pipe Network Modelling 


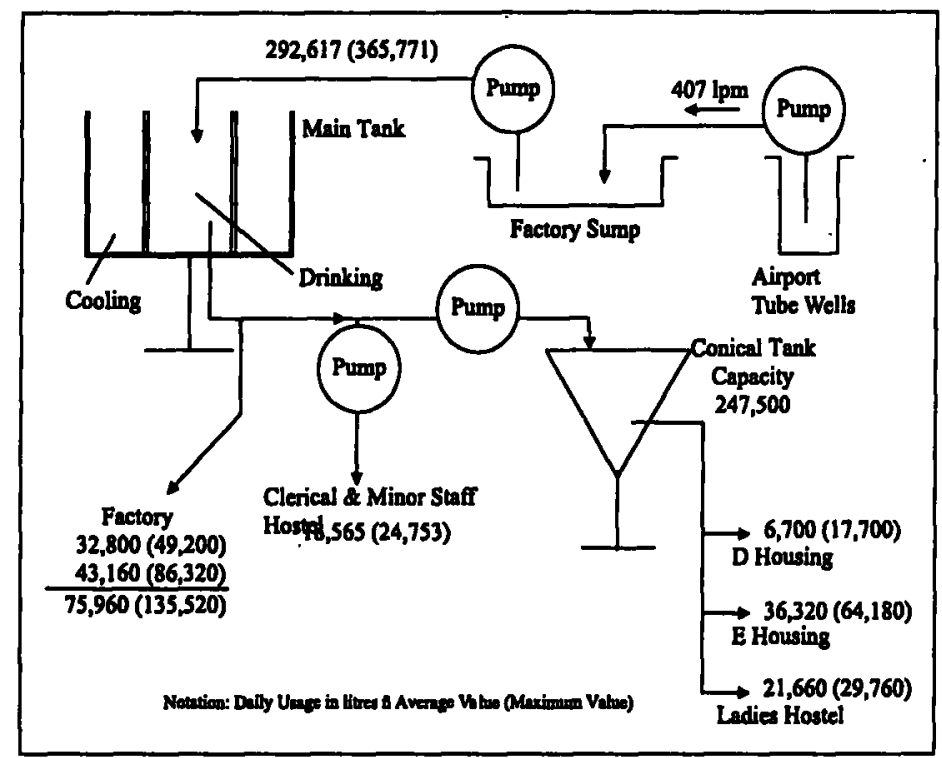

Figure 5: Components of the Drinking Water System and Water Balance

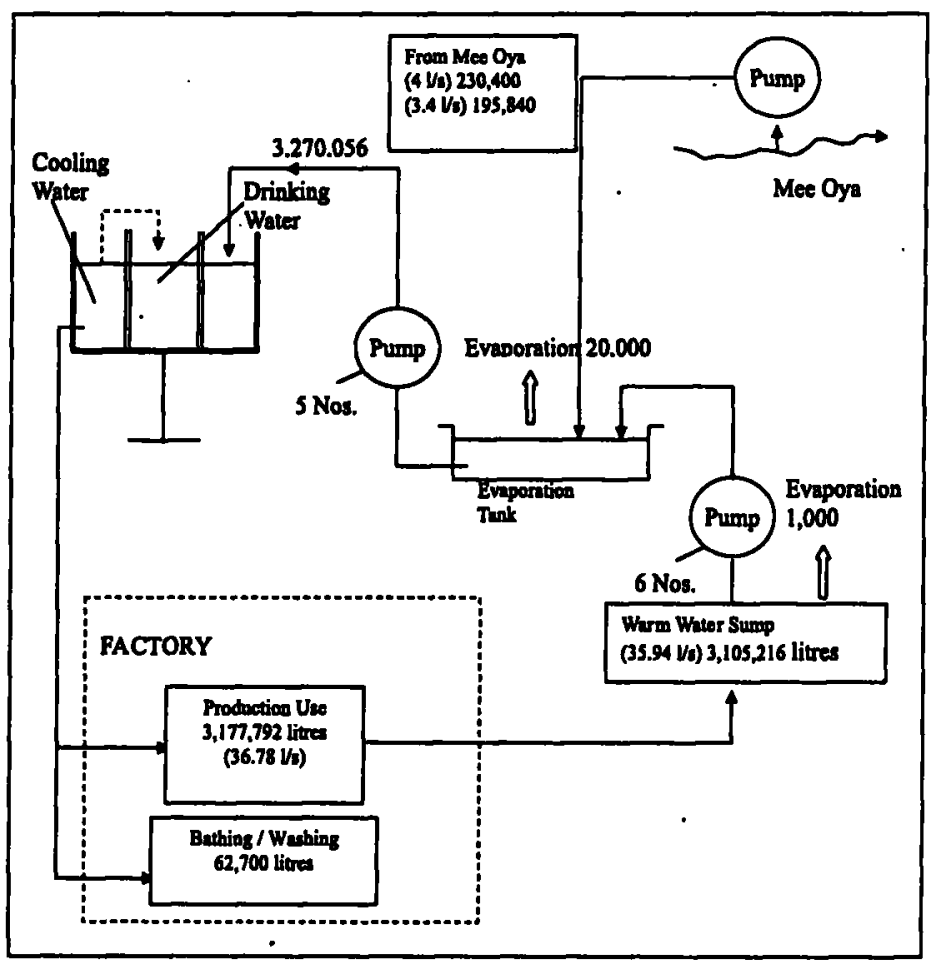

Figure 6: Components of the Cooling Water System and Water Balance

ensuring the topographical continuity of groundwater flow. Assuming uniform properties within each cell, grids were varied to obtain an acceptable uniform size. Model grids were established with 60 rows from North to South and 40 columns from East to West. Depth of each section was taken as the thickness of each layer. The calibrated and verified model was subsequently used to analyse the water balance, the effects of additional wells, the effect of changes to the recharge area and the study of water level fluctuations in case of droughts and seasonal fluctuations.

\subsubsection{Surface Water Supply System}

Mee Oya watershed was mathematically modelled using a conceptual rainfall-runoff model and was verified to identify the sustenance of water extraction from this surface water body. This model used a cascade of three linear reservoirs to represent the watershed (Figure 8). Modelling was carried out at a monthly time 
resolution and the watershed response to $75 \%$ probable rainfall was studied to identify the capability of the Mee Oya to supply the present quantity of water in the long term.

\subsubsection{Evaporation Tank and Water Quality}

Energy balance computations were carried out at the evaporation pond which is for the cooling of heated water released from the factory.

Analysis included identifying possible alternatives for the pond arrangement and computing the effectiveness of the same for requisite recommendation. Energy balance identified that the evaporation pond needs to be made efficient and hence two principal scenarios were incorporated for the purpose of selecting the best option. These were, 1) Incorporation of an opaque cover over the pond while enabling free circulation of ambient air for evaporative cooling, and 2) Introduction of three baffle surfaces in order to enhance the convective heat transfer through increased effectiveness.

Quality of sources of water to the cement factory and housing complex including the distribution system was analysed for thirteen chemical parameters, four physical and microbiological constituents. The microbiological parameters were restricted to total and faecal coliforms. Water quality test results of nine selected samples were looked at in comparison with accepted standards and also in terms of professional experience.

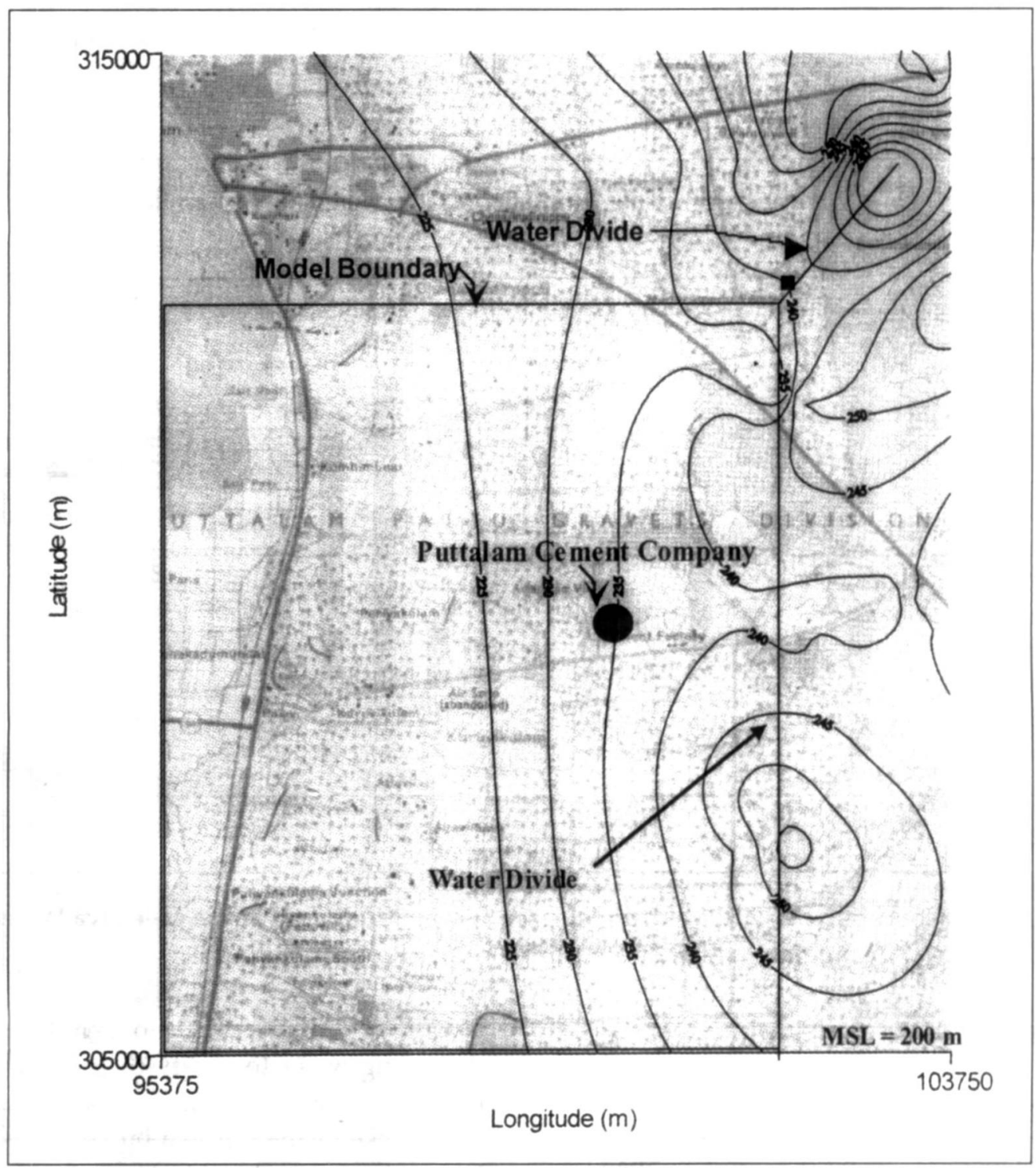

Figure 7: Groundwater Contours and the Groundwater model Boundary 


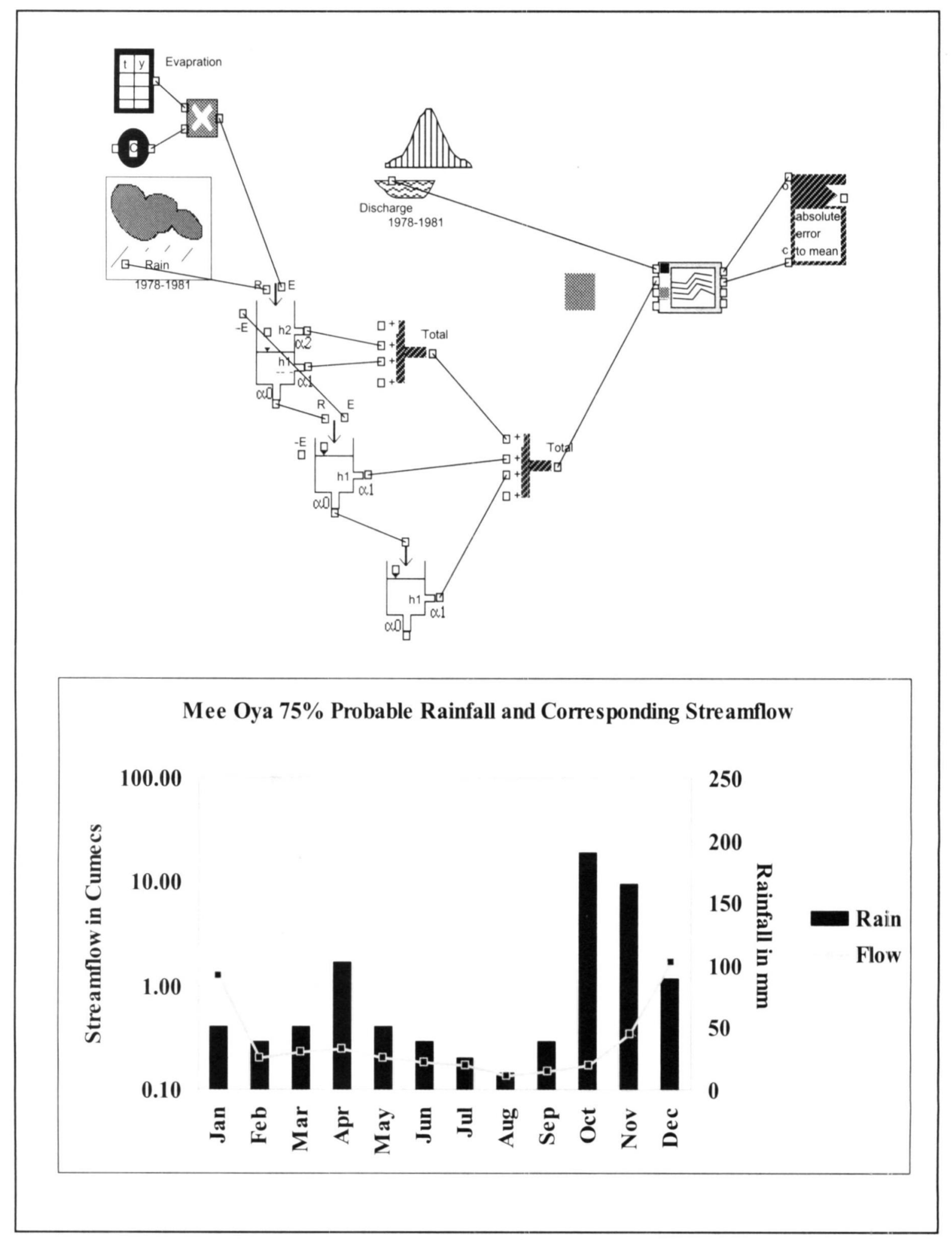

Figure 8: The Conceptual Hydrologic Model Used for the Modelling of the Mee Oya Watershed and the Watershed Response to $75 \%$ Probable Rainfall.

\section{Results and Discussion}

\subsection{Pipe Network}

Field and laboratory inspections and the analysis of pipe network identified significant clogging of smaller diameter pipes and much lesser clogging in the larger diameter pipes. In general network layout was found satisfactory and capable of delivering water to satisfy the needs. Storage network status was poor. Significant number of tanks lacked valves or had broken valves. Most tanks were cracked and leaking. Access to most overhead tanks and especially to the main cylindrical tank in the factory and conical tank at the housing area was very poor. 
The network if consisted of new pipes showed sustainable for an equal demand of $0.12 \mathrm{l} / \mathrm{s}(180$ $1 / d)$ by each user connection. Equal deterioration level analysis using a common demand of 0.1 litre per second indicated that the network does not effectively function beyond a clogging situation represented by a friction coefficient 80 since pressures in some nodes fall below zero. Study of varying friction shows that observations during field measurements are falling much below the levels indicated by uniform clogging. This confirms that there is significant reduction of diameters at various parts of the network. Analysis imposing clogging conditions to various house links by means of increased friction and reduction of diameter could match the observed pressures quite satisfactorily. The system performance was checked and best ways of incorporating various management options such as ball valves, establishing additional links etc., were found effective.

\subsection{Water Balance}

In the system for drinking purposes, water balance computations done by equating inflow outflow and change in storage indicate (Figure 6) that at average consumption levels the system losses about 133,402 litres per day. Total loss at maximum consumption level is about 93,800 litres per day. These losses are approximately $25-45 \%$ of the quantity supplied by the tube wells. The results indicate a daily average drinking water use of about 300,000 litres and water balance computations show that the average waste is nearly $46 \%$.

Water balance in the cooling system indicates that an approximate quantity of 3.17 million litres is for the cooling at production lines. As such about 30,000 litres are lost in the factory washing / bathing area probably due to overflow from tanks. Quantity of water leaving the kilns and mill is 3.10 million litres and this shows a loss of nearly 72,000 litres occur within the process of cooling. Though the quantity appears as large, it amounts to about $2 \%$ of the use for production process cooling. Losses in the factory washing and bathing amount to about $51 \%$. These values for losses in the system incorporate an upper-end pump loss of 1000 litres per pump and evaporation loss of 21,000 litres taken for water balance. Therefore, about $2-3 \%$ of the water taken in is lost in the cooling process. Cooling water consumed for other purposes such as washing and bathing show that about $40 \%$ of the supply is unaccounted for. The present quantity of extraction from the tube well near the $C$ housing is about 38,000 litres per day and it was found that consumption is nearly 18,500 litres per day more than the standard norms use $d$ for water supply systems elsewhere in the country.

Water mains from Mee Oya and tube wells near the old airstrip supply water to a few users other than the factory and the housing. Rate of pumping indicates a high level of extraction that does not justify the quantities received or extracted by other listed users. These pipes were identified as clogged due to scaling.

\subsection{Groundwater, Surface Water and Quality Concerns}

Groundwater testing of five tube wells indicated that two of the wells do not provide an adequate yield for economical operation. Two wells near the old airstrip show the availability of approximately 300 litres per minute per well. Well near the housing unit block called $\mathrm{C}$ which is close to the factory indicate a safe yield of about 200 litres per minute. Aquifer modelling indicated that if the Puttalam Cement Company desires then the construction of an additional well to extract 1000 cubic meters per day near the air port wells, would not have any significant impact on the groundwater system. Modelling emphasised the need to preserve the recharge area to the North West of factory premises for the long-term sustainability of groundwater.

Surface water source was found to run dry during many dry seasons. However, the flow of Mee Oya throughout the year with $75 \%$ probable rainfall as input was very much above the water quantity presently extracted for factory use.

Computations done for the evaporation tank revealed that the net heat gain through radiation is much higher than the net process heat component. The need to facilitate mixing of water in the evaporation pond was identified as a measure to ensure better efficiency. Therefore it was identified that a baffle system would enhance the heat transfer. Study of two alternative scenarios indicated that a combination of scenarios where a system of baffles and a roof would suit best for the given conditions. 


\subsection{Recommendations}

The study of the entire water supply and distribution system enabled the identification of the needs and constraints in various segments of the network. The following recommendations were made for sustainable management of water within the Puttalam Cement Company.

1. Clean the entire network incorporating necessary provisions such as washout valves to carryout periodical cleaning. Clean and repair the storage tank network and provide safe access for maintenance.

2. Repair and/or fix new control valves to the storage facilities to ensure system pressure head build up and minimise water overflow. Self control valves are recommended because it was found that they could raise system pressure heads in a stepwise manner as and when tanks get filled.

3. Incorporate recommended pipe links to have a looped network to enable pressure increase in poorly served areas.

4. Install water meters to main supply lines from Mee Oya \& old airstrip tube wells, drinking \& cooling outlets of the central overhead tank, inlet to the factory cooling system, outlet of the conical tank and outlet of the $\mathrm{C} 2$ groundwater well for better water management.

5. Attend to the pump leaks and other minor repairs. Pumps to be operated according to a schedule. Actual operation records for each pumping station to be maintained for effective management of water and energy.

6. Tube wells need to be cleaned of debris, pumps to be serviced, and riser mains to be repaired where necessary. Wells to be maintained in a concealed manner and pumping schedules to be drawn up and pumping records to be maintained.

7. As built plans and relevant records to be maintained in case of all future repairs or modifications done to the system. In future modifications, efforts should be taken not to make haphazard connections. Pipe lengths and proper joints need to be incorporated to avoid many pipe joints at very close proximity.
8. Routine patrolling system of the maintenance division needs to be strengthened to identify leaks and water overflows. Mechanisms need to be effected to inform the maintenance unit once the houses become vacant so that such houses could be inspected for any pipes left open.

9. User community groups to be formed and educated to shoulder more responsibilities with respect to efficient water management.

10. Water exchange between cooling to drinking and drinking to cooling to be avoided to maintain the quality of water.

11. Evaporation tank to incorporate a simple brick wall arrangement to ensure proper mixing of cooling water and a roof cover to reduce radiation heat gain.

\section{Conclusions}

1. A systematic engineering analysis incorporating a systems approach and tools such as water and energy balance enables a water manager to identify critical components and incorporate optimum cost options.

2. Water distribution pipe network models and hydrologic models calibrated and verified accordingly enables a manager to compare numerous management visions such as replacing the existing pipe network with new, opening up new links, addition of controls, expansion of the sus and modifications to network, possibility of expansions in distribution and supply etc., considering the quantities and pressures in the system.

3. In water infrastructure projects that require a critical analysis but experiencing deficiency in historical data needs carefully planned data collection programs and an engineering approach considering the characteristic of water to arrive at solutions that could be implemented. This approach provides low cost diagnostic options avoiding the elimination of hugh investments for comprehensive data collection programs.

4. The significant clogging of PVC pipes especially the smaller diameter pipes indicated the need of periodical cleaning to ensure the functions of the pipe network 
envisaged at the design. This was a deviation from the common acceptance that PVC pipes need no periodical cleaning due to its smooth inner surface.

5. In the dry zone regions where day time temperatures are high there can be significant radiation heat gains even in the warm water bodies that are exposed to the sun light.

\section{Acknowledgements}

The authors would like to show the appreciation to the Puttalam Cement Company for entrusting the work and also the Department of Civil Engineering of the University of Moratuwa for the encouragement and support to carryout projects that would contribute to the activities of the industry.

\section{References}

Wijesekera et al 2000

Wijesekera N.T.S., Peiris T.A., Gamage N.P.D., Kodippli A.A., Ghanapala P.P., Amarasinghe C.B., Ginige G.K. De S., Study on Water Supply System of the Puttalam Cement Company Limited, Final Report submitted to the Puttalam Cement Company Limited by the Department of Civil Engineering of University of Moratuwa, June 2000 